Review began 02/13/2022 Review ended 02/14/2022 Published 02/16/2022

๑) Copyright 2022

Busbaih et al. This is an open access article distributed under the terms of the Creative Commons Attribution License CC-BY 4.0., which permits unrestricted use, distribution, and reproduction in any medium, provided the original author and source are credited.

\section{Giant Breast Lipoma: A Case Report}

Zaki Busbaih ${ }^{1}$, Ali A. Almohammed Saleh ${ }^{2}$, Maitha K. AlMaghlouth ${ }^{2}$, Abdulqader M. Albeladi ${ }^{3}$, Tayseer Alali ${ }^{1}$, Mohammad S. AlGhadeer ${ }^{1}$, Ahmad Odeh ${ }^{1}$

1. General Surgery, Prince Saud Bin Jalawi Hospital, Al-Mubarraz, SAU 2. Medical School, King Faisal University, Hofuf, SAU 3. General Surgery and Laparoscopy, Prince Saud Bin Jalawi Hospital, Al-Mubarraz, SAU

Corresponding author: Ali A. Almohammed Saleh, ali.almohammedsalih@hotmail.com

\section{Abstract}

Lipomas are slow-growing, benign mesenchymal masses. Most lipomas are small, weighing only a few grams; however, if their size becomes exceptionally large, they are called giant lipomas. Giant lipoma of the breast is infrequently observed due to the rarity of size and location, with very few case reports available in the literature. Here, we report the case of a 48-year-old female patient who presented with a painless, huge lump in her right breast. The patient underwent surgical removal of the mass with a histologic examination confirming the diagnosis of a giant breast lipoma.

Categories: General Surgery

Keywords: excision surgery, lipoma, breast mass, giant lipoma, benign breast condition

\section{Introduction}

Lipoma is one of the most common benign neoplasms, derived from fatty tissue, and represents $16 \%$ of all mesenchymal tumors [1]. Lipomas usually occur in the age group of 40-60 years. They are slow-growing, without pain or functional impairment [2]. Lipomas are usually freely mobile underneath the skin and develops as well-circumscribed, encapsulated masses [3]. They are mostly small (less than $5 \mathrm{~cm}$ in diameter) with a weight of a few grams only [4]. They could occur in any part of the body and $20 \%$ are located in the chest wall [5]. Breast lipomas are usually small and may be difficult to diagnose due to the normal adipose tissue of the breast [6]. When the diameter of a lipoma is at least $10 \mathrm{~cm}$ or its weight exceeds 1,000 grams, it is considered as giant lipoma [7]. A giant breast lipoma is a rare manifestation so making a correct diagnosis is crucial in the prevention of the overtreatment of this mass, which otherwise may be managed as a malignant tumor. Here, we report a rare case of a 48 -year-old female patient with a giant lipoma in the right breast measuring $30 \times 18 \times 3 \mathrm{~cm}$ causing breast asymmetry.

\section{Case Presentation}

A 48-year-old female presented to the surgery clinic with a painless lump in her right breast for three years. The lump grew gradually in size. The patient is medically free with no previous history of breast trauma or disease. She has a history of tongue papilloma that was excised five years ago. She did not have a family history of breast carcinoma. Physical examination of the right breast revealed a well-defined, homogeneous, firm, non-tender, mobile mass, measuring approximately $30 \times 18 \times 3 \mathrm{~cm}$ in diameter, with dilated veins on the surface. The overlying skin of the mass and the nipple-areola complex appeared to be normal. There was no nipple discharge. Axillary lymphadenopathy was not present. The left breast examination was unremarkable.

Mammogram images revealed a right breast replacement by a huge homogeneously isoechoic encapsulated mass with an internal tiny cyst with peripheral calcification measuring about $16 \times 14 \mathrm{~cm}$ causing medial compression of the breast tissue. No skin thickening or nipple retraction was observed. There was no intralesional vascularity or enlarged axillary lymph nodes detected (Figure 1). 


\section{Cureus}

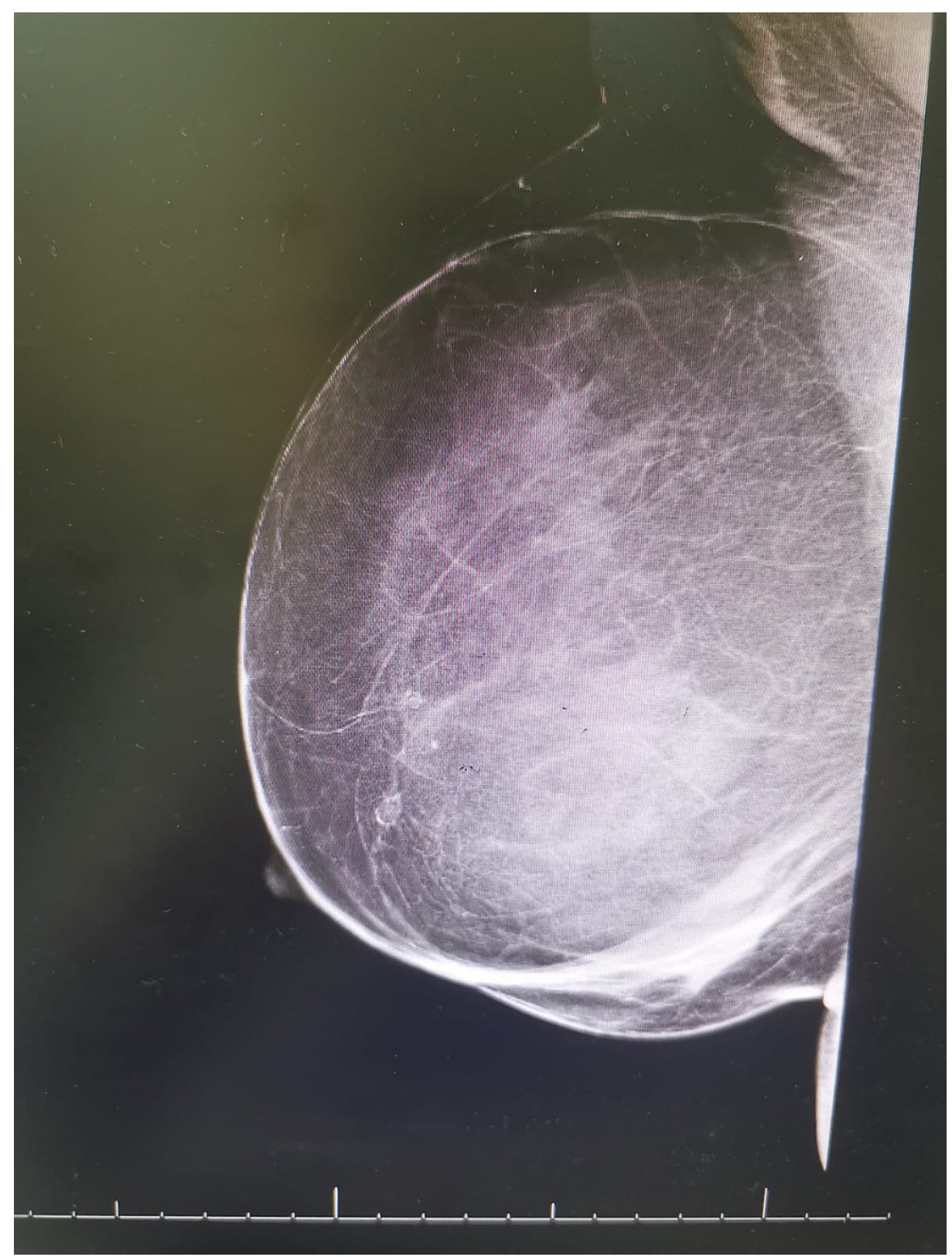

FIGURE 1: Mammographic view of the right breast shows several round, well-circumscribed, encapsulated, radiolucent masses.

In correlation to the mammogram, it represented a large lipoma with central fat necrosis, consistent with breast imaging-reporting and data system (BI-RADS) assessment category 2 , showing benign findings. Fine needle aspiration cytology (FNAC) was not performed as it was not needed.

An elective surgical excision was scheduled and performed under general anesthesia. The patient was placed in the supine position on the table; aseptic technique was followed, and draping was provided. The right breast revealed an intracapsular, lobular, solitary mass. A skin incision was made around the areola followed by dissection around the lipoma to excise it. The mass weighed $1000 \mathrm{~g}$ (Figure 2). 


\section{Cureus}

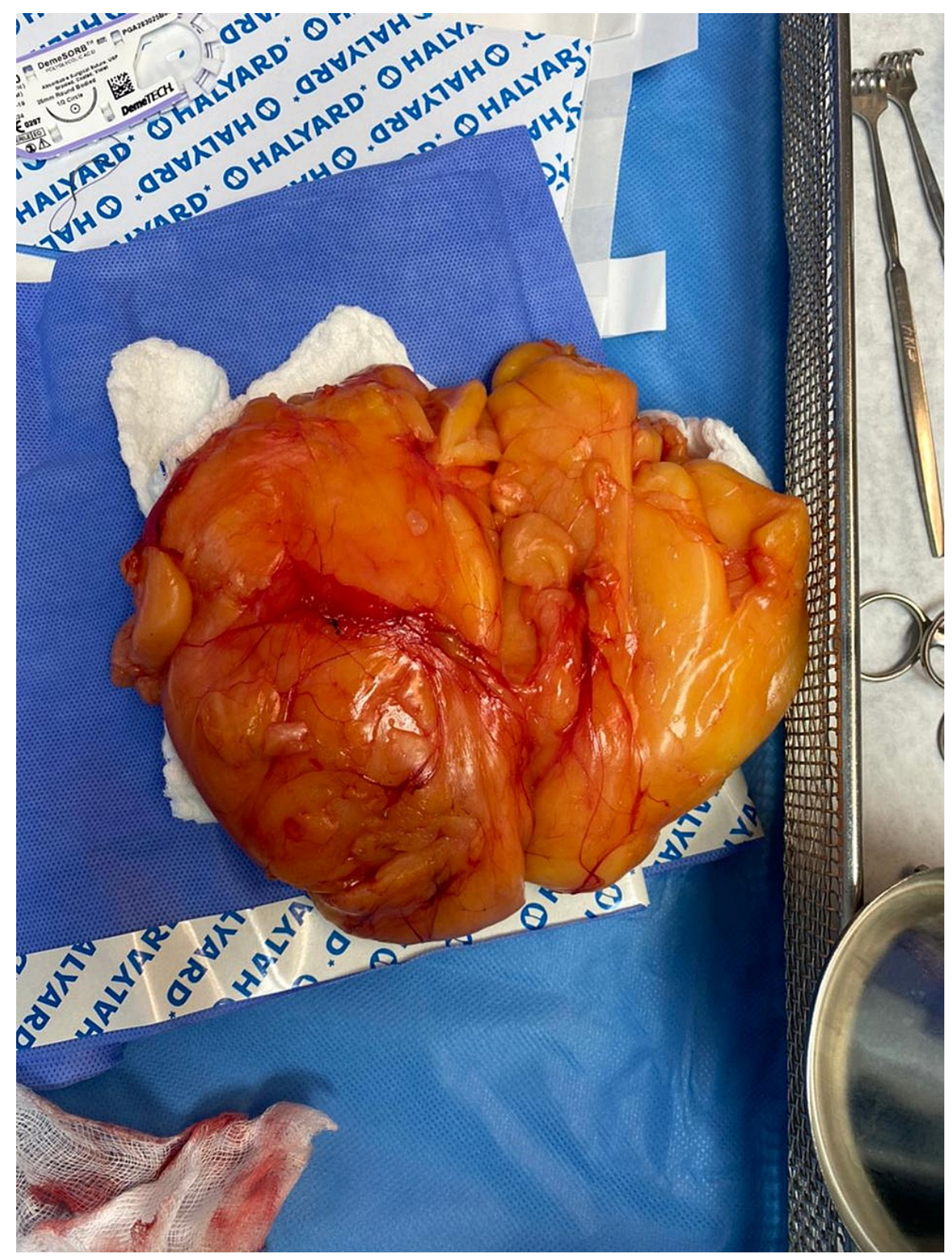

FIGURE 2: Gross appearance of the mass.

Hemostasis was achieved with electrocautery. Washing and drain insertion were applied under negative pressure. Closure was done intradermally with a subcuticular suture, and a pressure dressing was applied. Histopathologic examination of the specimen revealed one huge soft consistency, irregular surface, and yellow-colored tissue measuring $30 \times 18 \times 3 \mathrm{~cm}$. Cut sections showed adipose tissue without evidence of atypia or malignant change. The findings were consistent with lipoma of the breast. The patient had an uneventful postoperative course. She was discharged the next day after drain removal, to be followed up in the outpatient clinic.

\section{Discussion}

Lipomas are one of the most common adipose tumors. They are usually benign, well-circumscribed, and covered by a thin capsule [8]. The etiology of lipomas remains unidentified. However, it has been shown to be sporadic or linked to an inherited condition $[9,10]$. They can arise in any part of the body, with a prevalence rate of 2.1 per 1000 people [9]. Of lipomas, $20 \%$ are found in the chest wall, and the breast is a common site for this pathology $[5,11]$. They vary in size with the vast majority being small in size weighing only a few grams [11]. Hawary et al. defined a giant breast lipoma by the presence of a lesion with a

dimension of at least $5 \mathrm{~cm}$ and a weight more than $500 \mathrm{~g}$ [12]. However, according to Sanchez et al., a giant lipoma has a dimension of $10 \mathrm{~cm}$ [7]. A mass that weighed $5700 \mathrm{~g}$ and measured $35 \times 23 \times 20 \mathrm{~cm}$, reported by Ribeiro et al., appears to be the largest in literature [13]. Lipomas are usually solitary but might be hard to detect in large or postmenopausal breasts [14]. 
Patients typically present when lipomas cause anatomical changes that may lead to cosmetic concerns or interfere with function [15]. The presence of size disparity and architectural distortion mandates a comprehensive history, clinical examination, and investigations [16]. Because of the post-traumatic fat necrosis, lipomas may also appear as firm, fixed masses that may be clinically misinterpreted as malignancies [17]. Imaging techniques such as ultrasonography and mammography prove to be beneficial and useful for a more accurate diagnosis, especially in tailoring a specific management plan for every patient [6]. On mammography, a radiolucent nodule surrounded by a thin radiopaque capsule that may include ring-like calcifications owing to fat necrosis can establish the diagnosis of a lipoma. A correct diagnosis is critical since breast lipomas can be misdiagnosed as malignancies, phyllodes tumors, fibroadenomas, and duct papillomas [18]. Achieving the correct diagnosis might be challenging, necessitating an invasive approach such as FNAC or punch biopsy [17]. According to Lanng et al, the diagnosis of breast lipoma can be a diagnostic dilemma with difficulties in establishing the diagnosis through clinical examination, imaging studies, and FNAC [1]. In our case, FNAC was not done as the diagnosis was established according to the mammogram findings and confirmed through the histopathological examination that was done after the excision of the mass. Santi et al. reported a similar case of a 27-year-old female who presented with significant breast asymmetry. Preoperatively, she was diagnosed with breast liposarcoma. After excision and histopathology study was done, the result revealed the presence of a giant breast lipoma measuring $15.5 \times 9.3$ $\times 4.5 \mathrm{~cm}$ and weighing 257 grams; on histopathology, a uniform fatty composition with benign adipocytes was discovered [19].

Surgical excision has been the mainstay of treatment for lipoma historically. However, advanced medical treatment might cause a reduction in lipoma size. Two to three injections of deoxycholate have shown a decrease in approximately $75 \%$ of the lesion size in a case series [20]. Liposuction-assisted excision could be also considered as another definitive management of lipoma [7]. This technique is preferred in areas where larger scars should be avoided because it allows the incision to be placed in an inconspicuous location [21]. Although it's associated with better cosmetic results, it has been shown to increase the risk of recurrence and hematoma formation due to incomplete capsule removal [7]. Furthermore, skin irregularities such as dimpling, numbness, paresthesia, and pigmentation changes are all common complications after the liposuction technique [22-23]. The main surgical indications for breast lipoma removal include cosmetic deformity, patient discomfort, and the rapid growth of the lump [15]. For many uncomplicated cases, the excision can be performed in the minor operating room under local anesthesia [24]. However, since our patient presented with a huge mass that may have invaded the deep fascia or muscles, we decided to manage the patient with an advanced procedure under general anesthesia. The skin incisions should follow the langer's lines and be elliptical in order to obtain the best cosmetic result [24]. Hematomas and seromas are considered the most common postoperative complications [25]. Giant breast lipomas always cause discomfort and heaviness in patients. So, surgical intervention is often required for cosmetic reasons or to alleviate the patient's symptoms [15].

\section{Conclusions}

Breast lipomas are usually observed when they reach considerable dimensions and produce breast asymmetries and cosmetic problems that determine the patient's need to proceed with surgery. Whenever breast lipomas are diagnosed, they should be entirely excised and sent for histopathological studies in order to confirm a positive diagnosis of benignity. Long-term follow-up is necessary since lipomas can relapse even after several years.

\section{Additional Information \\ Disclosures}

Human subjects: Consent was obtained or waived by all participants in this study. Conflicts of interest: In compliance with the ICMJE uniform disclosure form, all authors declare the following: Payment/services info: All authors have declared that no financial support was received from any organization for the submitted work. Financial relationships: All authors have declared that they have no financial relationships at present or within the previous three years with any organizations that might have an interest in the submitted work. Other relationships: All authors have declared that there are no other relationships or activities that could appear to have influenced the submitted work.

\section{References}

1. Lanng C, Eriksen BØ, Hoffmann J: Lipoma of the breast: a diagnostic dilemma . Breast. 2004, 13:408-11. 10.1016/j.breast.2004.04.011

2. Pandya KA, Radke F: Benign skin lesions: lipomas, epidermal inclusion cysts, muscle and nerve biopsies Surg Clin North Am. 2009, 89:677-87. 10.1016/j.suc.2009.03.002

3. Ramírez-Montaño L, Vargas-Tellez E, Dajer-Fadel WL, Espinosa Maceda S: Giant lipoma of the breast. Arch Plast Surg. 2013, 40:244-6.

4. Grossman J, Menes T, Lahat G, Gur E, Weiss J, Barnea Y: Use of the oncoplastic reduction pattern technique following removal of a giant breast lipoma. Ann Plast Surg. 2011, 67:106-8. 10.1097/SAP.0b013e3181f3e3cc

5. Cappabianca Salvatore, Barberi Antonio, Walter Del Vecchio, et al.: Giant infiltrating lipoma of the face: CT and MR imaging findings. Am J Neuroradiol. 2003, 24:283-6.

6. Li YF, Lv MH, Chen LF, Wu YF: Giant lipoma of the breast: a case report and review of the literature . Clin 
Breast Cancer. 2011, 11:420-2. 10.1016/j.clbc.2011.04.005

7. Sanchez MR, Golomb FM, Moy JA, et al.: Giant lipoma: case report and review of the literature . J Am Acad Dermatol. 1993, 28:266-8. 10.1016/S0190-9622(08)81151-6

8. Rydholm A, Berg NO: Size, site and clinical incidence of lipoma. Factors in the differential diagnosis of lipoma and sarcoma. Acta Orthop Scand. 1983, 54:929-34. 10.3109/17453678308992936

9. Silistreli OK, Durmuş EU, Ulusal BG, Oztan Y, Görgü M: What should be the treatment modality in giant cutaneous lipomas? Review of the literature and report of 4 cases. Br J Plast Surg. 2005, 58:394-8. 10.1016/j.bjps.2004.09.005

10. Leffell DJ, Braverman IM: Familial multiple lipomatosis: report of a case and a review of the literature . J Am Acad Dermatol. 1986, 15:275-9.

11. Hakim E, Kolander Y, Meller Y, Moses M, Sagi A: Gigantic lipomas. Plast Reconstr Surg. 1994, 94:369-71. 10.1097/00006534-199408000-00025

12. Hawary MB, Cardoso E, Mahmud S, Hassanain J: Giant breast tumors. Ann Saudi Med. 1999, 19:174-6. 10.5144/0256-4947.1999.174

13. Ribeiro RC, Saltz R, España Quintera LF: Breast reconstruction with parenchymal cross after giant lipoma removal. Aesthetic Plast Surg. 2008, 32:695-7. 10.1007/s00266-008-9164-4

14. Schmidt J, Schelling M, Lerf B, Vogt M: Giant lipoma of the breast. Breast J. 2009, 15:107-8. 10.1111/j.15244741.2008.00681.x

15. Çitgez B, Akgün I, Ferhatoğlu F, Kartal A, Akçakaya A: Case report: giant lipoma of the breast. Breast Case. 2012, 1:20-22.

16. Dooms GC, Hricak H, Sollitto RA, Higgins CB: Lipomatous tumors and tumors with fatty component: MR imaging potential and comparison of MR and CT results. Radiology. 1985, 157:479-83. 10.1148/radiology.157.2.4048459

17. Rodriguez LF, Shuster BA, Milliken RG: Giant lipoma of the breast. Br J Plast Surg. 1997, 50:263-5. 10.1016/S0007-1226(97)91157-7

18. Muttarak M, Chaiwun B: Imaging of giant breast masses with pathological correlation. Singapore Med J. 2004, 45:132-9.

19. delli Santi G, Bellioni M, Loreti A, Stagnitto D, La Pinta M, Dell'Osso A: Giant breast lipoma: a rare cause of breast asymmetry. Plast Reconstr Surg. 2006, 117:1068-9. 10.1097/01.prs.0000201322.91566.42

20. Rotunda AM, Ablon G, Kolodney MS: Lipomas treated with subcutaneous deoxycholate injections. J Am Acad Dermatol. 2005, 53:973-8. 10.1016/j.jaad.2005.07.068

21. Nichter LS, Gupta BR: Liposuction of giant lipoma. Ann Plast Surg. 1990, 24:362-5. 10.1097/00000637199004000-00011

22. Calhoun KH, Bradfield JJ, Thompson C: Liposuction-assisted excision of cervicofacial lipomas . Otolaryngol Head Neck Surg. 1995, 113:401-3.

23. Wilhelmi BJ, Blackwell SJ, Mancoll JS, Phillips LG: Another indication for liposuction: small facial lipomas . Plast Reconstr Surg. 1999, 103:1864-7. 10.1097/00006534-199906000-00008

24. Lee HE, Yang CH, Chen CH, Hong HS, Kuan YZ: Comparison of the surgical outcomes of punch incision and elliptical excision in treating epidermal inclusion cysts: a prospective, randomized study. Dermatol Surg. 2006, 32:520-5. 10.1111/j.1524-4725.2006.32105.x

25. Chandawarkar RY, Rodriguez P, Roussalis J, Tantri MD: Minimal-scar segmental extraction of lipomas: study of 122 consecutive procedures. Dermatol Surg. 2005, 31:59-63; discussion 63-4. 10.1111/j.15244725.2005.31005 